\title{
A STEREOTAXIC METHOD FOR SECTIONING THE CORPUS CALLOSUM IN CAT 1
}

\author{
F. Magn, ${ }^{2}$ M.D., R. Melzack, ${ }^{3}$ Ph.D. and C. J. SMrth, ${ }^{4}$ Ph.D. \\ Istituto di Fisiologia, Università di Pisa, and Centro di Neurofisiologia del Consiglio \\ Nazionale delle Ricerche, Sezione di Pisa, Italia
}

(Received for publication: October 22, 1959)

\section{INTRODUCTION}

Section of the corpus callosum as a technique for experimental investigation of the central nervous system has enjoyed a long history. The surgical approach usually entails wide exposure and then transection of the bundle with knife or spatula, as reported by Carville and Duret (1875), Myers (1956), Bianki (1958), and Sperry (1959). A somewhat more involved technique was used by Bremer and Stoupel (1957) and Bremer (1958), who made the actual transection with a wire which was heated by passing an electric current after it had been brought into contact with the callosum. Methods requiring a dorsal approach involve some risk of interrupting the normal blood supply to the cerebral cortex as a result of cutting the meninges to expose the callosum. Since the intervention is usually made to one side of the midline, the disturbance is likely to be more severe in one hemisphere, thus limiting the validity of interhemispheric comparisons. The extensive exposure and manipulation required to reach the structure often cause delay in recovery from operation.

We required a method of sectioning the corpus callosum which involved (1) minimal exposure of the brain, so as to avoid disruption of cerebral blood flow, and to permit ample room for installation of implanted electrodes; (2) reproducibility of lesions from cat to cat; and (3) a procedure not requiring expert surgical skill nor exacting a high mortality toll. Since existing techniques did not fulfill completely all of these criteria we devised the procedure described below and present it in the hope that in original or modified form it may prove useful to other investigators.

\section{METHOD}

The stereotaxic section of the eallosum requires 2 electrode carriers which hold sewing needles, in1 Supported by the office of Scientific Research of the
Air Research and Development Command, U.S. Air Force, Air Research and Development Command, U.S. Air Force, $61(052)-107$, and by the Hockefeller Foundation.

2 Now
Rockefeller Foundation Research Fellow at the 2 Now Rockefeller Foundation Research Fello

Curtin School of Medicine, Canberra, Australia. Rearch Now at Psychology Section, Massachusetts Institute of TechNow at Psychology Section, Massachusetts Institute of Technology.

4 Fulbright Research Scholar, on leave from Psychology Department, University of Michigan. stead of electrodes, so that the eye of the needle occupies the position normally occupied by the tip of an eleetrode. The needles are prepared by soldering standard sewing needles into the tip of a piece of hypodermic tubing and are calibrated in the standard manner. After the cat has been placed in the stereotaxic apparatus the medial calvarium is exposed; a strip of bone is removed baring the longitudinal sinus plus $2 \mathrm{~mm}$. on either side. The electrode carriers may now be moved into the correct A-P position. The dura mater below each needle, and slightly to one side, is slit for $2-3 \mathrm{~mm}$. with the tip of a sharp blade; care must be exercised to avoid

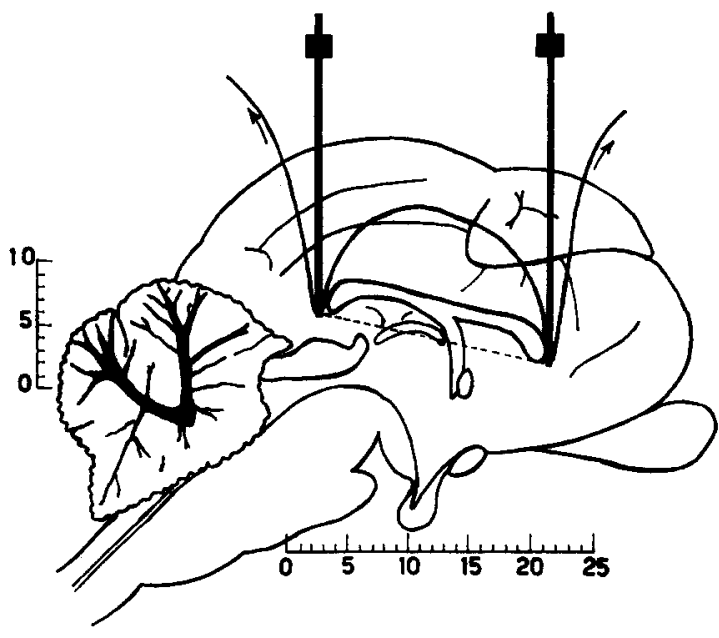

Fig. 1

Schemu of a stereotaxic method for sectioning the corpus callosum in cat. The two needles are shown just anterior and posterior to the callosum, a thread running loosely from one thread when tension (arrows) is anplled. Scale in millimeters.

damage to the longitudinal sinus. Now a thread must be passed under the dura so that the ends pass out through the two dural openings. A fine polyethylene cannula having the thread attached to one end is useful for this step. It is introduced into one of the dural holes, moved gently toward the other hole, and brought out the slit opening, carrying the thread with it. The cannula is now cut off, and the two needles on the electrode carriers are threaded. 
The dura and sinus are retraced gently, and the needles lowered into place at the rostral and caudal ends of the corpus callosum.

The needle which is to enter the genu of the callosum is moved into Horsley-Clarke coordinates: A21.5; LO; H1.5. The needle aimed for the splenium is lowered to A3; LO; H4.5.

One end of the thread is held firmly in each hand, and a gentle to-and-fro motion of the thread, drawing it more and more taut, causes it to slip down into the longitudinal fissure onto the corpus callosum. The motion is continued until the thread moves freely, indieating that the callosum has been eut. The thread may then be pulled out, and the electrode carriers are removed. Gelfoam is packed into the eranial defect to check any minimal bleeding that has been incurred. Closure of the skull defect and scalp wound is routine.

\section{RESULTS AND DISCUSSION}

The stereotaxic procedure described here has been used for sectioning the corpus callosum in each of fifteen cats; it was tolerated well by all animals. EEG records taken from screw electrodes placed lateral to the midline showed little sign of abnormality after the first few days, and we were able to confirm Bremer and Stoupel's (1957) observation of electrical asynchrony between the hemispheres after the cut.

Examination of the brains made at intervals of one to six months after operations showed that the corpus callosum was usually transected completely; the exceptions were in the cases of larger cats where the anterior or posterior extremes (or both) were spared. It appears then that a desirable refinement of the technique would include making a correction for the size of the cat. There were small traces of old bleeding along the eallosum, hut no signs of damage to structures below it. In two of our first animals some damage was inflicted upon midline cortex apparently due to a too brisk pressure applied to the string, hence our caution, in the Method, for gentle pressure.

\section{SUMMARY}

We have described a method by which the corpus callosum of the cat may be sectioned. Two needles are held in the electrode carriers of a standard Horsley-Clarke instrument and are positioned in front of and behind the corpus callosum. A thread running between them is brought under tension, pressing down on the callosal fibers and dividing them. Interference with cerebral circulation, operative trauma, and demands upon the operator's skill are minimized. The procedure has been carried out successfully on fifteen cats and appears to be readily adaptable to other laboratory animals.

\section{REFERENCES}

BIANKI, V. L. Effect of partial division of the corpus callosum in dogs on the differentiation of visual, auditory and cutaneous stimuli. Sechenov. physiol. J.U.S.S.R., 1958, 44: 660-667.

Bremer, F. Physiology of the corpus callosum. Res. Publ. Ass. nerv. ment. Dis., 1958, 36:424-448.

Bremer, F. et Stoupel, N. Recherche d'une participation du corps calleux au mécanisme de la synergie bio-électrique des hémisphères cérébraux. J. Physiol., Paris, 1957, 49: 66-67.

Carville, C. et Duret, H. Sur les fonctions des hé. misphères cérébraux. Histoire, critique et recherches expérimentales. Arch. Physiol. norm. path., $1875,7: 352-491$.

MYERS, R. E. Function of corpus eallosum in interocular transfer. Brain, 1956, 79 : 358-363.

SPERrY, R. W. Preservation of high-order function in isolated somatic cortex in callosum-sectioned cat. J. Neurophysiol., 1959, $22: 78-87$.

Reference: MaGNI, F., MaLZACK, R. and SMITH, C. J. A stereotaxic method for sectioning the corpus callosum in cat. EEG Clin. Neurophysiol., 1900, 12: $517-518$. 